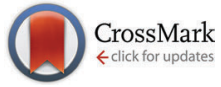

Cite this: J. Mater. Chem. C, 2016, 4, 1490

Received 4th January 2016 , Accepted 18th January 2016

DOI: $10.1039 /$ c6tc00021e

www.rsc.org/MaterialsC

\section{Preferential formation of columnar mesophases via peripheral modification of discotic $\pi$-systems with immiscible side chain pairs $\dagger$}

\begin{abstract}
Tsuneaki Sakurai, ${ }^{a b}$ Yusuke Tsutsui, ${ }^{b}$ Kenichi Kato, ${ }^{c}$ Masaki Takata ${ }^{c}$ and Shu Seki*ab
When sufficient volume of dodecyl chains are attached at one imide position of a perylenediimide (PDI) or naphthalenediimide (NDI) core and triethyleneglycol (TEG) chains on the other side, the resulting

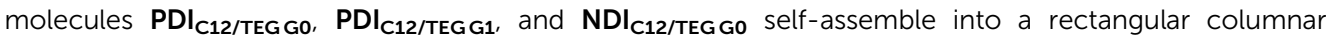
mesophase with p2mg symmetry, forming hydrophobic/hydrophilic nano-segregation of side chains. The driving force of PDI $_{\text {C12/TEG Go }}$ to form preferentially the rectangular columnar mesophase is given by the immiscibility between the side chain pairs-exclusion of other phases such as cubic, crystalline and amorphous phases, where thermodynamically unstable contacts between hydrophobic and hydrophilic chains considerably take place. In contrast, this preference is less found in the analogous molecules decorated with either dodecyl or TEG chains at both termini. PDI ${ }_{\mathrm{C} 12 / \mathrm{C} 12 \mathrm{GO} \text { and PDI }}$ aEG/TEGGo form a hexagonal columnar mesophase because of the optimized chain/core volume. However, if the side

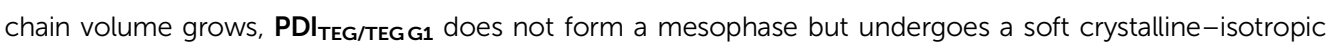
phase transition, while $\mathrm{PDI}_{\mathrm{C12/C12} \mathrm{G} 1}$ was revealed to destabilize its columnar mesophase but forms a micellar cubic phase. $\mathrm{NDI}_{\mathrm{C12/C12G0}}$ resulted in a strong crystallization, while $\mathrm{NDI}_{\mathrm{TEG} / \mathrm{TEGGO}}$ formed amorphous liquid. The molecular design strategy using immiscible side chain pairs potentially enables a variety of $\pi$-systems to stack up to form a columnar phase rather than other ordered phases, regardless of the chain/core volume balance.
\end{abstract}

\section{Introduction}

Columnar liquid crystals (LCs) based on discotic $\pi$-systems have attracted interest due to their potential use as soft organic semiconductors with unidirectional charge carrier transporting properties. $^{1-3}$ If the methodology to obtain columnar mesophases with largely $\pi$-conjugated cores by rational molecular design strategies is established, we can use various active $\pi$-systems as photo and electronic devices. For discotic LC molecules, the major driving force to enable columnar structures via self-assembly is mostly given by the peripheral modification of disc-shaped cores with long paraffinic chains, ${ }^{4-7}$ where rigid $\pi$-systems and flexible side chains are segregated in

\footnotetext{
${ }^{a}$ Department of Molecular Engineering, Graduate School of Engineering, Kyoto University, Kyotodaigaku-katsura, Nishikyo-ku, Kyoto 615-8510, Japan. E-mail: sakurai-t@moleng:kyoto-u.ac.jp, seki@moleng.kyoto-u.ac.jp; Fax: +81-75-383-2572; Tel: +81-75-383-2572

${ }^{b}$ Department of Applied Chemistry, Graduate School of Engineering, Osaka University, 2-1 Yamadaoka, Suita, Osaka 565-0871, Japan

${ }^{c}$ RIKEN SPring-8 Center, 1-1-1 Kouto, Sayo-cho, Sayo-gun, Hyogo 679-5148, Japan $\dagger$ Electronic supplementary information (ESI) available: Detailed synthetic procedures of materials, UV-vis spectra, temperature dependent XRD patterns and DSC thermograms. See DOI: 10.1039/c6tc00021e
}

a nanoscopic scale. Nevertheless, the volume balance between a discotic core and peripheral chains has a remarkable impact on the stable phase structures, ${ }^{8}$ leading to the formation of other phases such as micelle cubic, ${ }^{9-11}$ bicontinuous cubic, ${ }^{12-14}$ crystalline, ${ }^{15,16}$ and amorphous phases. ${ }^{17,18}$ Therefore, in order to obtain columnar LC materials, the try-and-error in the synthesis process is required for every discotic $\pi$-system such as changing the number and length of chains. Here we demonstrate a potentially general molecular design strategy using an immiscible side chain pair ${ }^{19-26}$ (Fig. 1) that preferentially induces the formation of a rectangular columnar mesophase rather than other non-columnar phases. As a proof of this strategy, we selected typical n-type semiconducting cores, perylenediimide $(\mathrm{PDI})^{27,28}$ and naphthalenediimide (NDI), ${ }^{29,30}$ that are easily available for site-specific introduction of different side chain functionalities. ${ }^{31,32}$ As an immiscible chain pair, dodecyl (hydrophobic) and triethyleneglycol (hydrophilic) chains were adopted and introduced into the imide positions of the PDI or NDI cores. Since contact between hydrophobic and hydrophilic


molecule having the immiscible side chain pair (Fig. 1), allows discotic cores to avoid the phase structures containing large intermolecular paraffinic-oxyethylene contacts and thus eventually 

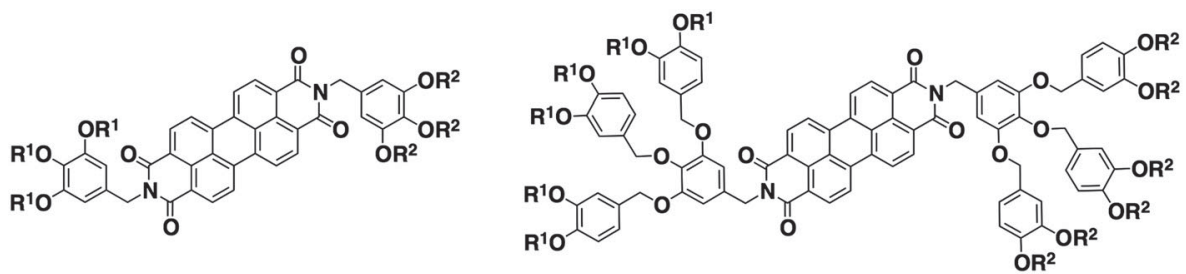

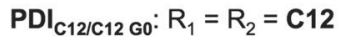

$$
\begin{aligned}
& \mathrm{PDI}_{\text {C12/TEG G0 }}: \mathrm{R}_{1}=\mathrm{C12}, \mathrm{R}_{2}=\text { TEG } \\
& \mathrm{PDI}_{\text {TEG/TEG GO }}: \mathrm{R}_{1}=\mathrm{R}_{2}=\mathrm{TEG}
\end{aligned}
$$

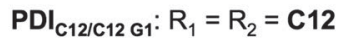

$$
\begin{aligned}
& \mathrm{PDI}_{\text {C12/TEG G1 }}: \mathrm{R}_{1}=\mathrm{C12}, \mathrm{R}_{2}=\mathrm{TEG} \\
& \text { PDI }_{\text {TEG/TEG G1 }}: R_{1}=R_{2}=\text { TEG }
\end{aligned}
$$

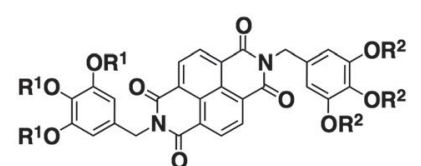

$\mathrm{NDI}_{\mathrm{C} 12 / \mathrm{C} 12 \mathrm{GO}}: \mathrm{R}_{1}=\mathrm{R}_{2}=\mathrm{C} 12$

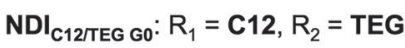

NDI $_{\text {TEG ITEG GO }}: R_{1}=R_{2}=$ TEG

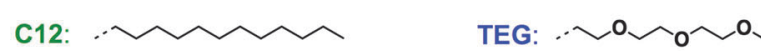

Fig. 1 Molecular structures of the perylenediimide (PDI) and naphthalenediimide (NDI) derivatives with hydrophobic and/or hydrophilic peripheral side chains.

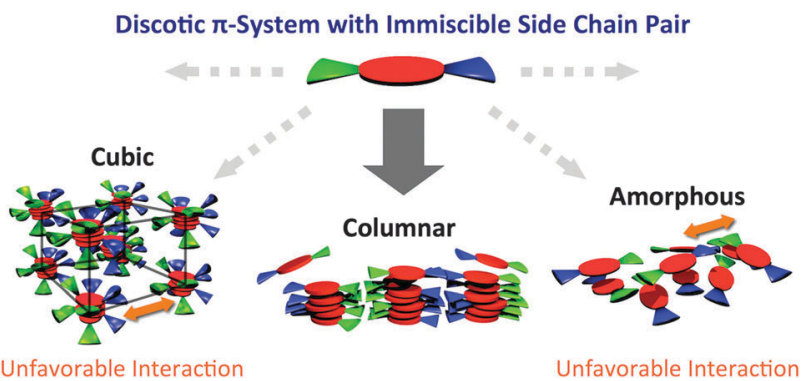

Discotic $\pi$-System with Simple Paraffinic Chains

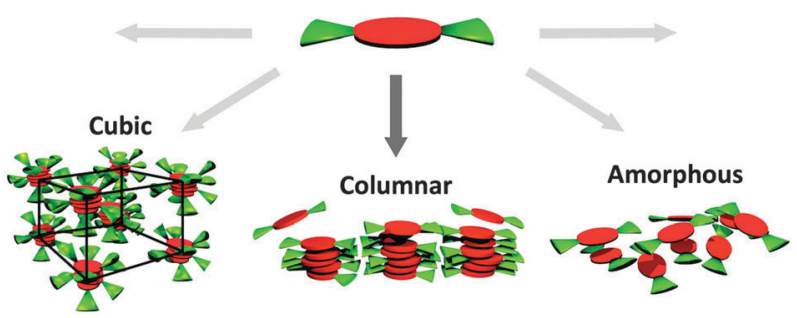

Fig. 2 Conceptual illustrations of the preferential formation of columnar mesophase via peripheral modification of immiscible side chain pairs. The orange arrows indicate thermodynamically unfavourable contacts.

form a columnar structure with hydrophobic/hydrophilic nanosegregated layers (Fig. 2). Of interest, we found that this preference was also confirmed when the volume balance between the core and side chains is changed as seen in $\mathbf{P D I}_{\mathbf{G 1}}$ and $\mathbf{N D I}_{\mathbf{G O}}$ series (Fig. 1). These results support our concept and propose a potentially general molecular design strategy to realize selfassembled columnar structures from a variety of large planar $\pi$-systems.

\section{Results and discussion}

\section{Synthesis}

The PDI derivatives PDI C12/Teg go, PDI $_{\text {TEg/Teg Go, PDI }}$ C12/C12 G1, PDI $_{\text {C12/TEg G1, and PDI }}$ TEG/TEg G1 (Fig. 1) were newly synthesized through the reaction using perylenetetracarboxylic dianhydride and taper-shaped amine compounds having dodecyl or TEG

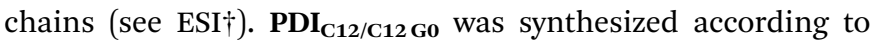
the reported procedures with a slight modification. The NDI derivatives were also prepared by following the similar synthetic schemes used in the PDI synthesis. Isolation and purification were successfully carried out by column chromatography using silica gel, followed by the recycling preparative size-exclusion chromatography, and then reprecipitation (see ESI $\dagger$ ). All the PDI and NDI compounds were fully characterized by ${ }^{1} \mathrm{H}$ and ${ }^{13} \mathrm{C}$ NMR spectroscopy and MALDI-TOF-MS spectrometry (see ESI $\dagger$ ).

\section{Liquid crystalline property of G0-PDI derivatives}

Differential scanning calorimetry (DSC) revealed that $\mathbf{P D I}_{\mathbf{C 1 2} / \mathbf{C 1 2} \mathbf{G o}}$ showed a mesophase from -30 to $220{ }^{\circ} \mathrm{C}$ in the second cooling process at a rate of $10{ }^{\circ} \mathrm{C} \min ^{-1}$ (Table 1 and Fig. S1, ESI $\dagger$ ). In the mesophase, birefringent textures were observed in polarized optical microscopy (POM) (Fig. 3a) while the mesophase structure was assigned to a columnar hexagonal lattice by means of X-ray diffraction analysis (XRD), both of which are consistent with the previous reports. ${ }^{33,34}$ From the (100) diffraction peak in the XRD pattern, a lattice parameter $a=30.9 \AA$ at $70{ }^{\circ} \mathrm{C}$ was disclosed, and one relatively broad peak was assigned to a $\pi$-stacking periodicity of $c=3.4 \AA$ (Fig. 4a). In the solid state below $c a$. $-30{ }^{\circ} \mathrm{C}$, the observed diffraction peaks in its XRD pattern became obviously broad (Fig. S3, ESI $\dagger$ ) though the set of the peaks was still assigned to a hexagonal lattice, indicating that the material was in a LC-glass phase $^{35}$ (Table 1). The diffraction corresponding to the $\pi-\pi$ plane was confirmed at all the measured temperatures below the clearing point. In fact, spin-coated thin films of PDI $_{\mathbf{C 1 2} / \mathbf{C 1 2} \text { Go }}$ afforded electronic absorption spectra typical of H-type $\pi$-stacked PDI aggregates (Fig. 5a), ${ }^{36}$ displaying a blue shift and broadening of the absorption bands at around $500 \mathrm{~nm}$ compared to that in a good solvent such as $\mathrm{CHCl}_{3}$.

With these results in mind, the other compounds were characterized in the identical manner. When cooled down from

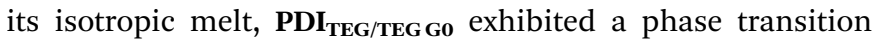
into a mesophase at $168{ }^{\circ} \mathrm{C}$ in which the dendritic texture developed in POM (Fig. 3c). The lower clearing point than that of PDI $_{\mathbf{C 1 2} / \mathbf{C 1 2} \text { Go }}$ probably originates from the more flexible 
Table 1 Phase behaviors with transition temperatures $\left({ }^{\circ} \mathrm{C}\right)$ and enthalpy changes $\left(\mathrm{kJ} \mathrm{mol}^{-1}\right)$ in the second heating/cooling process. Scanning rate was $10^{\circ} \mathrm{C} \mathrm{min}^{-1}$. The symbols $\mathrm{G}, \mathrm{Cr}, \mathrm{Col}_{h}, \mathrm{Col}_{r}, \mathrm{Cub}, \mathrm{X}$, and Iso in the phase behaviors denote liquid crystalline glassy, crystalline, hexagonal columnar, rectangular columnar, micellar cubic, unidentified, and isotropic phases, respectively. Symbol * indicates the observation of clear $\pi-\pi$-stacking periodicity in XRD

\begin{tabular}{|c|c|c|c|c|}
\hline Entry & Phase & $\mathrm{e} \stackrel{T_{\mathrm{t}} /{ }^{\circ} \mathrm{C}\left(\Delta H / \mathrm{kJ} \mathrm{mol}^{-1}\right)}{\gtrless}$ & Phase & \\
\hline PDI $_{\mathrm{C} 12 / \mathrm{C} 12 \mathrm{GO}}$ & $\mathrm{G}^{*}$ & $\underset{-30(-16.3)}{\stackrel{-25(18.1)}{\rightleftarrows}} \mathrm{Col}_{\mathrm{h}}{ }^{*}$ & $\underset{220(-12.3)}{\stackrel{223(13.7)}{\rightleftarrows}}$ Iso & \\
\hline PDI $_{\text {C12/TEG GO }}$ & $\mathrm{Cr}$ & $\underset{18(-21.8)}{\stackrel{23(24.6)}{\longrightarrow}} \mathrm{Col}_{\mathrm{r}}^{* a}$ & $\underset{112(-1.1)}{\stackrel{113(0.8)}{\rightleftarrows}} \operatorname{Col}_{\mathrm{h}}{ }^{*}$ & $\underset{191(-7.6)}{\stackrel{194(7.7)}{\rightleftarrows}}$ Iso \\
\hline $\mathrm{PDI}_{\text {TEG/TEG GO }}$ & $\mathrm{Cr}^{*}$ & $\underset{46(-1.9)}{\stackrel{59(2.3)}{\rightleftarrows}} \mathrm{Col}_{\mathrm{h}}{ }^{*}$ & $\underset{168(-5.5)}{\stackrel{171(5.4)}{\rightleftarrows}}$ Iso & \\
\hline PDI $_{\mathrm{C} 12 / \mathrm{C12} \text { G1 }}$ & $\mathrm{G}^{*}$ & $\underset{-3(-61.3)}{\stackrel{2(54.5)}{\rightleftarrows}} \mathrm{Col}_{\mathrm{h}}{ }^{*}$ & $\underset{90(-7.8)}{\stackrel{135(20.6)}{\rightleftarrows}} \mathrm{Cub}$ & $\underset{186(-6.5)}{\stackrel{191(3.0)}{\rightleftarrows}}$ Iso \\
\hline PDI $_{\text {C12/TEG G1 }}$ & $\mathrm{Cr}^{*}$ & $\underset{-3(-26.7)}{\stackrel{0(17.7)}{\rightleftarrows}} \mathrm{Col}_{\mathrm{r}}^{* a}$ & $\underset{147(-10.8)}{\stackrel{150(15.1)}{\rightleftarrows}} \mathrm{X}$ & $\underset{154(-1.9)}{\stackrel{155(1.5)}{\rightleftarrows}}$ Iso \\
\hline PDI $_{\text {TEG/TEG G1 }}$ & $\mathrm{Cr}$ & $\underset{89(-12.6)}{\stackrel{100(14.0)}{\longrightarrow}}$ Iso & & \\
\hline $\mathrm{NDI}_{\mathrm{C} 12 / \mathrm{C} 12 \mathrm{GO}}$ & $\mathrm{Cr}_{1}$ & $\underset{59(-61.9)}{\stackrel{69(60.9)}{\rightleftarrows}} \mathrm{Cr}_{2}$ & $\underset{76(-11.2)}{\stackrel{78(8.1)}{\rightleftarrows}} \mathrm{Col}_{\mathrm{r}}^{b}$ & $\underset{132(-27.8)}{\stackrel{142(26.4)}{\rightleftarrows}}$ Iso \\
\hline $\mathrm{NDI}_{\mathrm{C} 12 / \mathrm{TEG}} \mathrm{GO}$ & $\mathrm{Cr}_{1}^{*}$ & $\underset{34(-7.9)}{\stackrel{40(9.3)}{\rightleftarrows}} \mathrm{Cr}_{2}^{*}$ & $\underset{57(-7.7)}{\stackrel{68(6.3)}{\rightleftarrows}} \mathrm{Col}_{\mathrm{r}}^{* a}$ & $\underset{76(-18.7)}{\stackrel{98(19.2)}{\rightleftarrows}}$ Iso \\
\hline $\mathrm{NDI}_{\text {TEG/TEG G0 }}$ & Iso & & & \\
\hline
\end{tabular}

nature of TEG than that of dodecyl chains, which was often seen in the previous reports. ${ }^{37}$ In addition, XRD analysis revealed that the observed mesophase was a hexagonal columnar phase with a $\pi-\pi$ distance of $c=3.4 \AA$ (Fig. 4d). The lattice parameter $a$ was

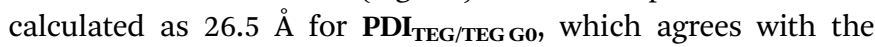
shorter chain length of TEG than that of dodecyl. One notable behavior of PDI TEG/TEG Go is that the phase transition at $46{ }^{\circ} \mathrm{C}$, detected by DSC measurements at $10{ }^{\circ} \mathrm{C} \mathrm{min}^{-1}$ upon cooling (Fig. S1, ESI $\dagger$ ), was not a LC/glass but LC/crystal transition. For example, the XRD pattern at $20{ }^{\circ} \mathrm{C}$ showed several minor but sharp diffraction peaks that did not appear at $80{ }^{\circ} \mathrm{C}$ (Fig. S5, ESI $\dagger$ ). The contrast was again explained by the flexibility of side chains. Upon cooling from the LC phase, dodecyl chains in PDI $_{\mathbf{C 1 2 / C 1 2 ~ G o ~}}$ have a driving force to interdigitate each other, resulting in the freezing of the hexagonal columnar structure and thus showing broad peaks in XRD. On the other hand, TEG chains have much smaller inter-chain interactions, as evident from the smaller enthalpy values upon the Cr-LC transition (Table 1). Therefore, PDI cores as well as benzyl units in PDI $_{\text {TEG/TEG Go }}$ can crystallize, as if in solution, into their stable packing structure. When focused on the melting points, it was found that the melting point of $\mathbf{P D I}_{\mathbf{T E G} / \mathbf{T E G ~ G o}}\left(52{ }^{\circ} \mathrm{C}\right)$ was higher than that of $\mathbf{P D I}_{\mathbf{C 1 2 / \mathbf { C 1 2 }} \mathbf{G 0}}\left(-28^{\circ} \mathrm{C}\right)$. However, this is a delicate issue that strongly relies on the substitution patterns of chains to the core. As discussed above, dodecyl chains represent stronger interchain interactions upon freezing (larger $\Delta H: 13.0 \mathrm{~kJ} \mathrm{~mol}^{-1}$ ). At the same time, they show a larger entropy loss (larger $\Delta S: 26.3 \mathrm{~J} \mathrm{~mol}^{-1}$ )
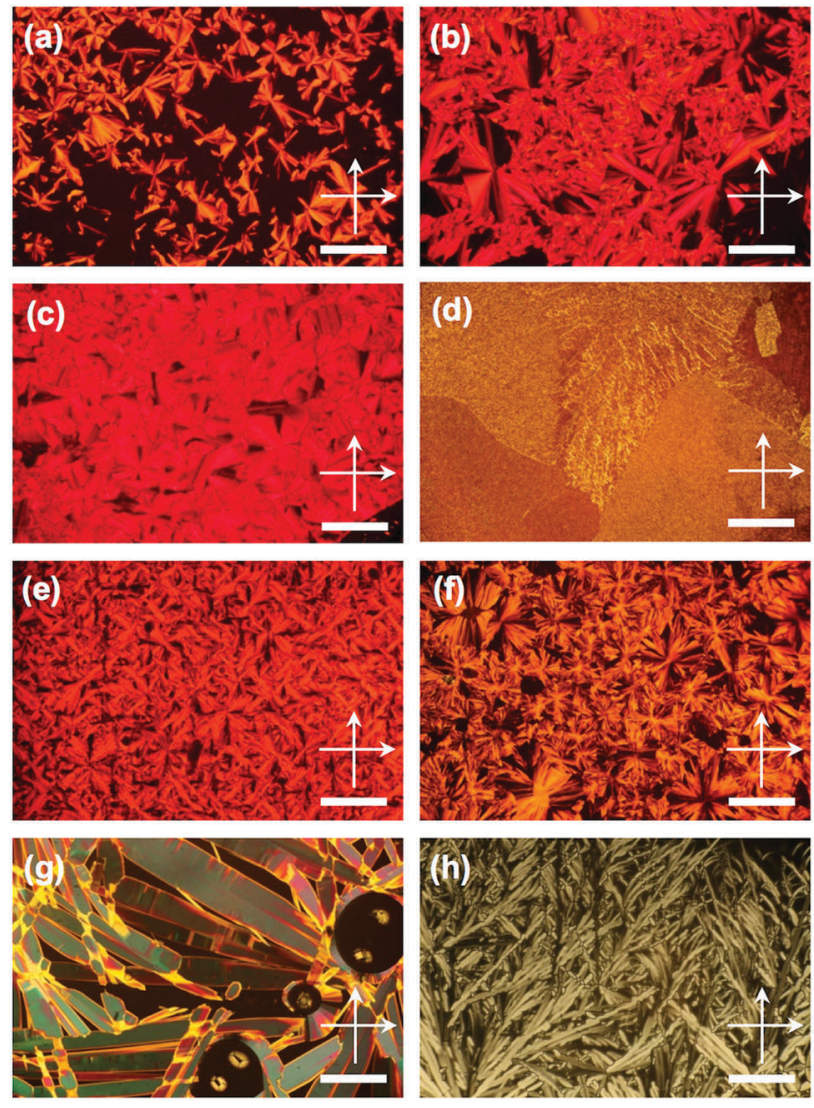

Fig. 3 Crossed polarized optical micrographs of (a) $\mathrm{PDI} \mathrm{C} 12 / \mathrm{C} 12 \mathrm{Go}_{\mathrm{G}}$ at $190^{\circ} \mathrm{C}$, (b) $\mathrm{PDI}_{\mathrm{C} 12 / \mathrm{TEG} G 0}$ at $180{ }^{\circ} \mathrm{C}$, (c) PDI $\mathrm{PEG}_{\mathrm{TE} / \mathrm{TEG}}$ at $160{ }^{\circ} \mathrm{C}$, (d) $\mathrm{PDI}_{\mathrm{C} 12 / \mathrm{C} 12 \mathrm{G} 1}$ at $90{ }^{\circ} \mathrm{C}$, (e) PDI $\mathrm{P} 12 / \mathrm{TEGG} 1$ at $148{ }^{\circ} \mathrm{C}$, (f) $\mathrm{PDI}_{\mathrm{TEG} / \mathrm{TEGG} 1}$ at $93^{\circ} \mathrm{C}$, (g) $\mathrm{NDI}_{\mathrm{C} 12 / \mathrm{C} 12 \mathrm{Go}}$ at $140{ }^{\circ} \mathrm{C}$ and (h) $\mathrm{NDI}_{\mathrm{C} 12 / \mathrm{TEGGO}}$ at $87^{\circ} \mathrm{C}$. Scale bars indicate $200 \mu \mathrm{m}$.

(Table S1, ESI $\dagger$ ). Because of this entropy-enthalpy compensation (Fig. S2, ESI $\dagger$ ), ${ }^{38}$ one cannot easily expect the melting point. In the present substitution pattern of the PDI $_{\mathbf{G O}}$ system, higher melting temperature was observed for $\mathbf{P D I} \mathbf{T E G}_{\mathrm{TE} / \mathrm{TEG} \text { Go }}$.

PDI $_{\text {C12/TEG G0 }}$ showed two mesophases in DSC at 18-112 and 112-191 ${ }^{\circ} \mathrm{C}$ upon $10{ }^{\circ} \mathrm{C}$ min $^{-1}$ cooling (Table 1, Fig. $3 \mathrm{~b}$ and Fig. S1, ESI $\dagger$ ). XRD measurements revealed that the highertemperature mesophase was assigned to a hexagonal columnar phase with a lattice parameter of e.g. $a=29.9 \AA$ and $c=3.5 \AA$ at $170{ }^{\circ} \mathrm{C}$ (Fig. 4b). In contrast, the lower-temperature mesophase was featured by its characteristic structural symmetry. For example, the (100) peak, usually not detected in common rectangular phases with high symmetry, was observed as seen in Fig. 4c. After complete assignment of all the clear diffraction peaks, we found that the LC phase at $170{ }^{\circ} \mathrm{C}$ was a rectangular columnar lattice with $p 2 m g$ symmetry, ${ }^{22,23}$ where the lattice parameters of $a$ and $b$ are 53.3 and $26.1 \AA$ at $90{ }^{\circ} \mathrm{C}$, respectively. This specific structure can be explained as a result of side-chain immiscibility. ${ }^{19-26}$

Namely, because of the enthalpic gain, dodecyl chains prefer to organize with themselves and vice versa for the TEG chains. Thus, to minimize the contact between dodecyl and TEG domains, PDI $_{\text {C12/TEG Go }}$ molecules stack up to form the columnar structure that further integrates into alternate immiscible nano-scale 

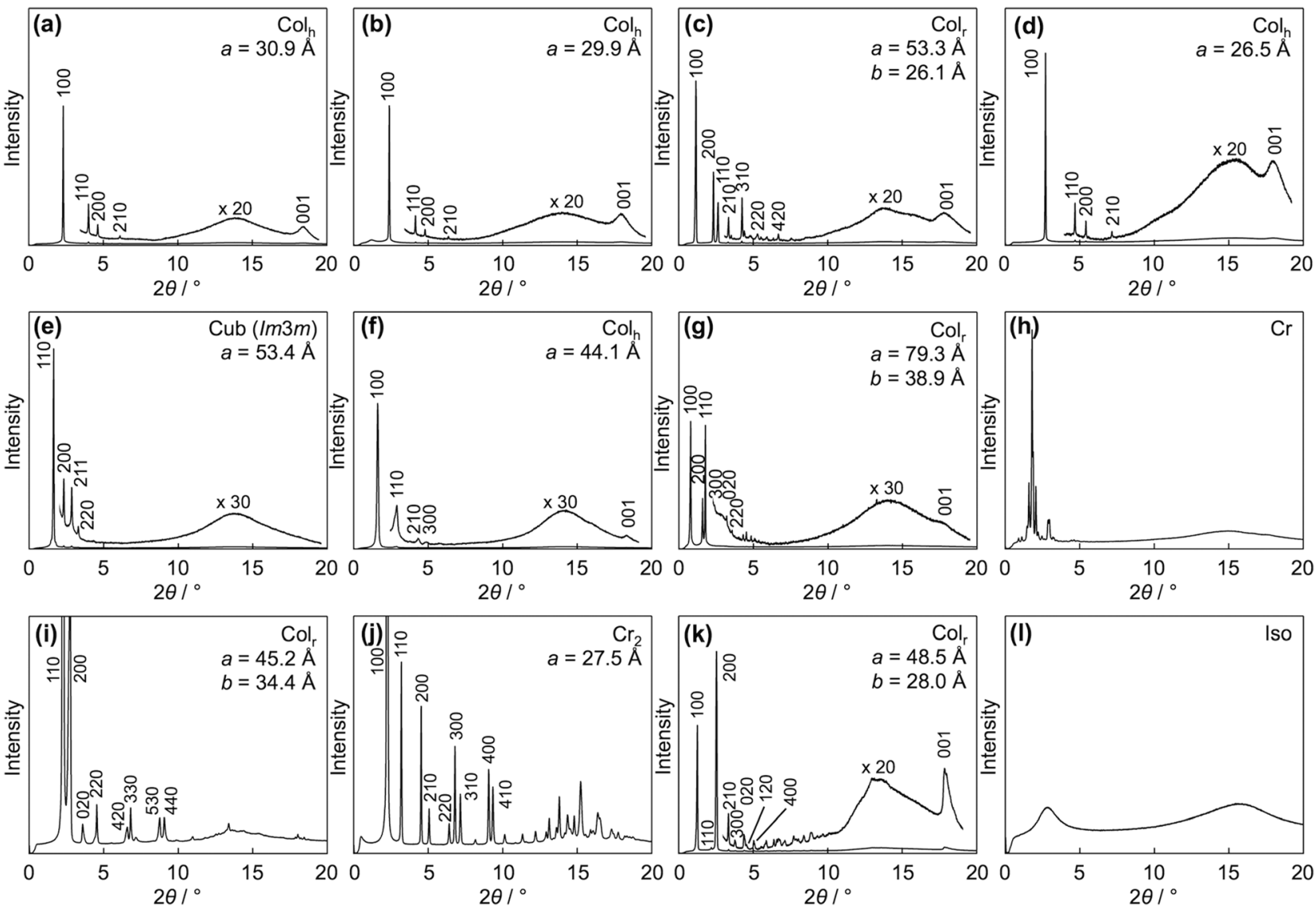

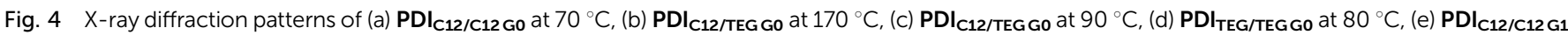

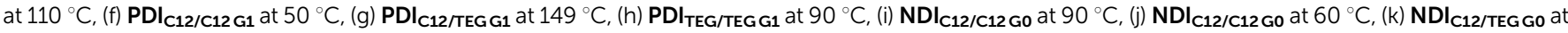
$90{ }^{\circ} \mathrm{C}$, and (l) $\mathrm{NDI}_{\mathrm{TEG} / \mathrm{TEGGO}}$ at $30^{\circ} \mathrm{C}$.
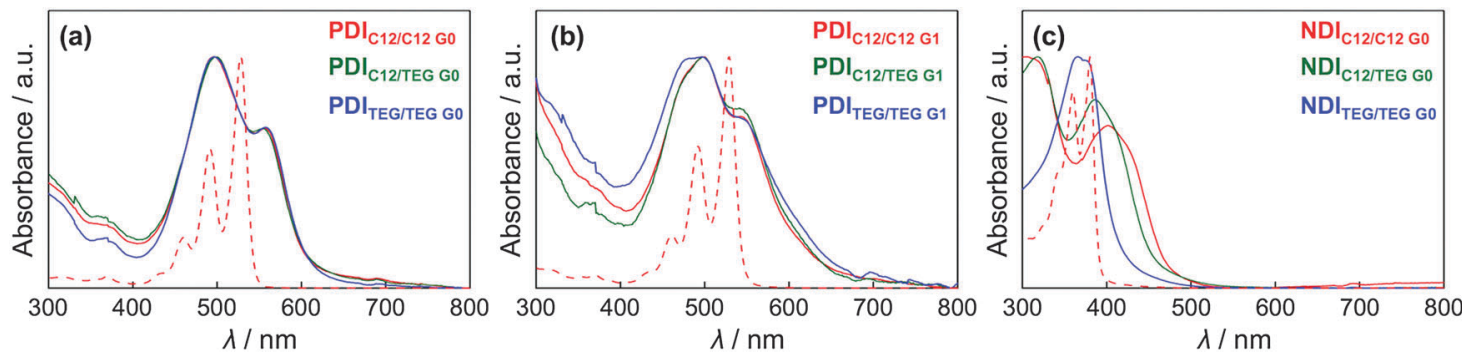

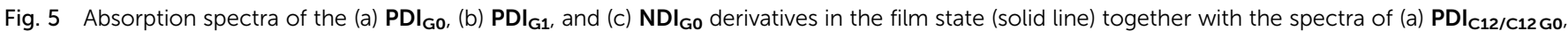
(b) $\mathrm{PDI}_{\mathrm{C} 12 / \mathrm{C1} 2 \mathrm{G1}}$, and (c) $\mathrm{NDI}_{\mathrm{C} 12 / \mathrm{C} 12 \mathrm{Go}}$ in $\mathrm{CHCl}_{3}$ (dashed line) at $25^{\circ} \mathrm{C}$.

layers (Fig. 6). Consequently, a rectangular columnar LC phase with $p 2 m g$ symmetry is realized. This mesophase structure, upon elevating the temperature, undergoes phase transition into the hexagonal columnar mesophase at $113^{\circ} \mathrm{C}$, which is probably due to the partially mixed dodecyl and TEG chains that lead to the higher-symmetry phase (Fig. 6). The above possible mechanism was also supported by another PDI derivative carrying dodecyl and semifluoroalkyl chains reported recently. ${ }^{39,40}$ We believe that the combined use of two immiscible chains as peripheral substituents generally enables a variety of $\pi$-conjugated motifs to form columnar mesophases. It should be noted that both PDI $_{\text {C12/TEG Go and }}$ PDI $_{\text {TEG/TEG Go }}$ displayed absorption spectra similar to that of
PDI $_{\mathbf{C 1 2 / C 1 2 ~ G 0}}$ in their spin-coated films (Fig. 5). We concluded that the actual $\pi$-stacking geometry of PDI units within a columnar structure is not essentially different among the three materials. We should mention the previous work by Thelakkat et al., ${ }^{32}$ where the modification by a pair of two-blanched immiscible chains results in the formation of hexagonal columnar mesophases. It suggested the importance of core/chain volume balances on the selection of hexagonal/rectangular geometry. ${ }^{26}$

\section{Liquid crystalline properties of G1-PDI derivatives}

Then our motivation moved on to the acceptable range of the proposed effect by immiscible side chains. We wondered that 


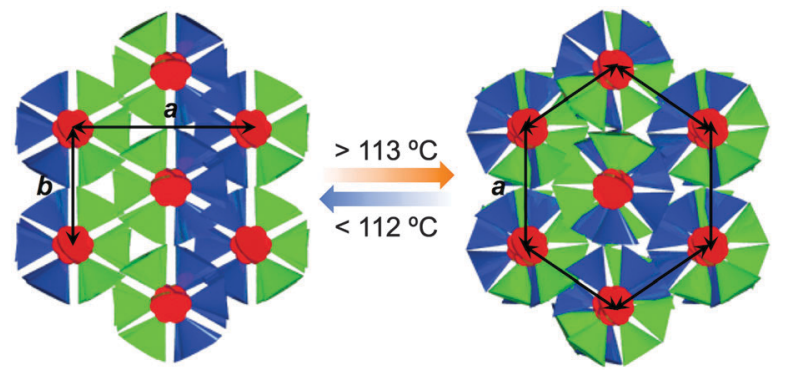

Fig. 6 Schematic illustrations of molecular arrangements in rectangular and hexagonal columnar phases observed in PDI $_{\mathrm{C} 12 / \mathrm{TEG} G 0}$ with a unit cell. The red discs and green/blue triangular prisms indicate PDI cores and hydrophobic/hydrophilic chain parts, respectively.

which type of mesophases appeared if the volume of the side chains get larger or smaller. For this purpose, $\mathbf{P D I}_{\mathbf{G} 1}$ series were prepared (Fig. 1). PDI $_{\mathbf{C 1 2} / \mathbf{C 1 2} \mathbf{G 1}}$ exhibited two mesophases at $-3-90{ }^{\circ} \mathrm{C}$ and $90-186{ }^{\circ} \mathrm{C}$ on second cooling (Table 1 and Fig. S1, ESI $\dagger$ ). However, no optical texture was appeared in POM above ca. $90{ }^{\circ} \mathrm{C}$, even though the isotropic melt of $\mathbf{P D I}_{\mathbf{C 1 2 / C 1 2} \mathbf{G 1}}$ was cooled down. The fact possibly reflects the presence of an opticallyisotropic but structurally-ordered mesophase. By means of XRD analysis, $\mathbf{P D I}_{\mathbf{C 1 2} / \mathbf{C 1 2} \mathbf{G 1}}$ at $110{ }^{\circ} \mathrm{C}$ gave a set of diffractions at $2 \theta=1.64,2.32,2.85$ and $3.28^{\circ}$ that are not assignable to common columnar phases (Fig. 4e). In fact, the higher-temperature mesophase was assigned to a micellar cubic phase with the $\operatorname{Im} 3 m$ symmetry. Considering the lattice parameter $a=53.4 \AA$ at that temperature, the probable molecular arrangement is composed of several stacks of PDI cores that are covered with a shell of dodecyl chains (Fig. 2 and 7). The reason of the formation of the micellar cubic phase is mostly the large volume of side chains. Nevertheless, when the temperature was decreased below $90{ }^{\circ} \mathrm{C}$ to reduce the contribution of the entropy term, PDI $_{\mathbf{C 1 2} / \mathbf{C 1 2} \text { G1 }}$ formed a hexagonal columnar phase (Fig. $4 \mathrm{f}$ and Fig. S6, ESI $\dagger$ ), which is indicative of the $\pi$-stacking capability among PDI chromophores (Fig. 5). Accordingly, birefringent textures developed at $90{ }^{\circ} \mathrm{C}$ under crossed polarized



Fig. 7 Summary of phase behaviors depending on side-chain substitution patterns demonstrated for PDI/NDI systems in this study. The orange, green, and blue parts indicate $\pi$-conjugated cores and hydrophobic and hydrophilic chains, respectively. conditions (Fig. 3d and Fig. S12, ESI $\dagger$ ). The large hysteresis of this first-order phase transition, confirmed by DSC measurements (Fig. S1, ESI $\dagger$ ), suggests that the structural transition from the micellar cubic to the hexagonal columnar phase takes a certain period of time to allow the huge volume of side chains to move and orient properly. Upon further cooling, $\mathbf{P D I}_{\mathbf{C 1 2} / \mathbf{C 1 2} \mathbf{G 1}}$, like $\mathbf{P D I}_{\mathbf{C 1 2 / C 1 2 ~ G o}}$, adopted a LC-glass state at a temperature below $c a .0{ }^{\circ} \mathrm{C}$ (Table 1 and Fig. S1, S6, ESI $\dagger$ ). This phase transition is mostly driven by a freeze of alkyl chains. The reason of higher transition temperature of $\mathbf{P D I}_{\mathbf{C 1 2} / \mathbf{C 1 2} \mathbf{G 1}}$ than that of $\mathbf{P D I}_{\mathbf{C 1 2} / \mathbf{C 1 2} \mathbf{G 0}}$ is attributed to the crowded environment of dodecyl chains. Upon melting of the chains along the glass-LC transition, dodecyl chains get a smaller degree of freedom as compared to the case of $\mathbf{P D I}_{\mathbf{C 1 2 / C 1 2} \mathbf{G 0}}$. Namely, the entropic gain per single chain is smaller for $\mathbf{P D I}_{\mathbf{C 1 2 / C 1 2} \mathbf{G 1}}$, whereas the enthalpic penalty may be comparable (Table S1, ESI $\dagger$ ), resulting in a higher transition temperature $\left(T_{\mathrm{G}-\mathrm{LC}}=\Delta H_{\mathrm{G}-\mathrm{LC}} / \Delta S_{\mathrm{G}-\mathrm{LC}}\right)$ for PDI $_{\mathrm{C} 12 / \mathrm{C12} \text { G1 }}$.

On the other hand, PDI $_{\text {TEG/TEG G1 }}$ showed a simple DSC curve basically containing one phase transition upon both heating and cooling processes (Table 1 and Fig. S1, ESI $\dagger$ ). Although birefringent textures appeared in POM at $93{ }^{\circ} \mathrm{C}$ (Fig. 3f), the lower-temperature phase is not liquid crystalline. For example, the obtained XRD pattern at $90{ }^{\circ} \mathrm{C}$ includes several notable diffraction peaks (Fig. $4 \mathrm{~h}$ and Fig. S8, ESI $\dagger$ ) that however were not assignable to simple columnar, lamellar, or cubic phases. We gave up clarifying the detailed phase structure and denoted it as an unidentified crystalline phase. In this solid phase, PDI $_{\text {TEG/TEG G1 }}$ contains $\pi$-stacked aggregates, which was proved by absorption spectral study in the film state (Fig. 5b). The absence of LC phase for PDI TEG/TEG G1 is most likely due to the bulky substituents with too fluidic TEG chains. TEG chains in this crowded environment do not receive the entropic gain enough for stabilizing the LC phase as a thermodynamically stable phase. This issue is delicate and difficult to discuss in a general manner.

PDI $_{\text {C12/TEG G1 }}$ showed two mesophases at $-3-147{ }^{\circ} \mathrm{C}$ and 147-154 ${ }^{\circ} \mathrm{C}$ (Table 1 and Fig. S1, ESI $\dagger$ ). Upon cooling from its isotropic melt, PDI $_{\mathbf{C 1 2 / T E G ~ G 1}}$ at $148{ }^{\circ} \mathrm{C}$ afforded birefringent focal-conic textures in POM, indicative of a columnar mesophase (Fig. 3e). Indeed, XRD measurements disclosed that the dominant diffraction peaks were assigned to (100), (200), and (110) in a rectangular lattice with the $p 2 m g$ symmetry, where the lattice parameters of $a$ and $b$ are 79.3 and $38.9 \AA$ at $149{ }^{\circ} \mathrm{C}$, respectively (Fig. 4g). Moreover, though the XRD patterns involved unidentified crystal-like peaks upon cooling in this mesophase (Fig. S7, ESI $\dagger$ ), still (100), (200) and (110) peaks in a rectangular lattice mainly appeared. Taking into account the $\pi$-stacking interactions among PDI units (Fig. 5), PDI $\mathbf{C 1 2 / T E G ~ G 1 ~}_{\text {was found }}$ to behave similar to $\mathbf{P D I}_{\mathbf{C 1 2 / T E G} \text { Go }}$ because of the modification with immiscible side chains. One distinct difference is the absence of a hexagonal columnar phase. If the $\mathbf{P D I}_{\mathbf{C 1 2 / T E G} \text { G1 }}$ molecules move significantly in translational or rotational directions, the mixing of large volume of dodecyl and TEG chains takes place, leading to a considerable enthalpic penalty. Therefore, PDI $_{\text {C12/TEG G1 }}$ maintains the rectangular columnar structure even 
upon elevating the temperature. Unfortunately, we could not obtain information of a higher-temperature mesophase at $147-154{ }^{\circ} \mathrm{C}$ (on cooling) despite the detailed VT-XRD measurements. The other interesting matter to note is that XRD patterns in the temperature region of the $\mathrm{Col}_{\mathrm{r}}$ phase showed broad diffraction at $2 \theta=c a$. 14 and $16^{\circ}$ (Fig. S7, ESI $\dagger$ ). These diffraction peaks strongly indicate the halo of dodecyl and TEG chains, respectively, which proves the presence of nanoscale immiscible domains.

Through the above experimental results, the peripheral modification of immiscible side chain pairs seems to extend the acceptable range of core/chain volume balance for columnar LC formation, whose driving force was given by the unstabilization of other possible mesophase candidates (Fig. 2 and 7).

\section{Liquid crystalline properties of G0-NDI derivatives}

For tuning the core/chains volume balance, there is another approach using smaller $\pi$-conjugated motifs than PDI without changing the G0-type peripheral units. For this purpose, we synthesized $\mathbf{N D I}_{\mathbf{G o}}$ series (Fig. 1) and investigated their phase transition behaviors and structural information. Based on the DSC curves scanned at a rate of $10{ }^{\circ} \mathrm{C} \mathrm{min}^{-1}, \mathbf{N D I}_{\mathbf{C 1 2} / \mathbf{C 1 2} \mathrm{Go}}$ has three solid and one isotropic liquid phases (Table 1 and Fig. S1, ESI $\dagger$ ). Upon cooling from its isotropic melt, $\mathbf{N D I}_{\mathbf{C 1 2} / \mathbf{C 1 2} \mathbf{G 0}}$ obviously crystallizes at $140{ }^{\circ} \mathrm{C}$ (Fig. 3g). The typical XRD patterns indicate the high crystallinity of all the three solid phases, though we only denote the highest-temperature mesophase as $\mathrm{Col}_{\mathrm{r}}$ (Fig. 4i, j and Fig. S9, ESI $\dagger$ ). In addition, judging from the XRD patterns (Fig. S9, ESI $\dagger$ ), the diffraction peak corresponding to the $\pi$-stacking periodicity, if any, was quite weak.

In contrast, NDI $_{\text {TEG/TEG Go }}$ forms isotropic liquid even at a room temperature. Its POM images are dark and only broad peaks were observed in its XRD patterns (Fig. 4l), while its DSC curves are almost planar (Fig. S1, ESI $\dagger$ ). Considering the behavior of

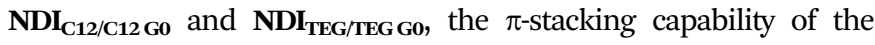
NDI system is so weak that the properties of side chains are dominant for the whole molecule- $-\mathbf{N D I}_{\mathbf{C 1 2} / \mathbf{C 1 2} \mathbf{G 0}}$ strongly crystallizes due to the interdigitation of dodecyl chains while NDI $_{\text {TEG/TEG Go }}$ is an isotropic liquid due to the flexibility of TEG chains.

Similar to $\mathbf{P D I}_{\mathbf{C 1 2} / \mathbf{T E g} \text { Go }}$ and $\mathbf{P D I}_{\mathbf{C 1 2} / \mathbf{T E g} \text { G1, }} \mathbf{N D I}_{\mathbf{C 1 2} / \mathbf{T E G} \text { Go }}$ forms a rectangular columnar phase with the $p 2 m g$ symmetry, which was confirmed by the presence of the 100 diffraction peak in XRD (Fig. 4k). Meanwhile, some hysteresis was observed in its DSC curves (Fig. S1, ESI $\dagger$ ) and minor but sharp diffractions were appeared in XRD (Fig. 4k and Fig. S10, ESI $\dagger$ ), both of which imply the crystalline nature of the materials. However, NDI C12/TEG Go $_{\text {has }}$ characteristic features different from those of $\mathbf{N D I}_{\mathbf{C 1 2} / \mathbf{C 1 2} \mathbf{G 0}}$.

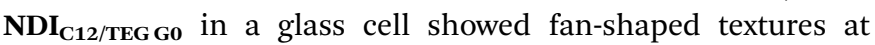
$140{ }^{\circ} \mathrm{C}$ in POM (Fig. 3h). Furthermore, it displayed a clear $\pi$-stacking periodicity of $c=3.46 \AA$ in XRD patterns (Fig. $4 \mathrm{k}$ and Fig. S10, ESI $\dagger$ ). Overall, immiscible chains play a role in forcing the NDI core to stack up in a columnar fashion, affording $p 2 m g$ rectangular columnar structures. When looking at the thermodynamic parameters, different behaviors of NDI series are obvious. By plotting the entropy and enthalpy values upon the LC-Iso phase transition (Fig. S2, ESI $\dagger$ ), the entropy-enthalpy compensation was confirmed. However, the linear correlation is different between the
PDI and NDI compounds having mesophases. The fact implies the large contribution of inter-chain interactions to the $\mathrm{Col}_{\mathrm{r}}$-Iso transitions that is not commonly observed for LC-Iso transitions. However, what we would like to emphasize here is that the immiscible side chain pairs work to develop the columnar mesophase with a periodically-stacked $\pi$-system in both LC

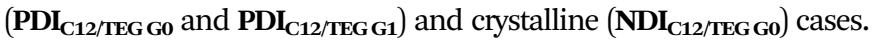

\section{Conclusions}

Motivated by our previous findings, ${ }^{22,23}$ where the modification with a immiscible side chain pair makes a $\pi$-system form a columnar liquid crystalline phase, here we have investigated the effect of immiscible side chain pairs on the mesomorphism of discotic $\pi$-systems in a more systematic and general way. We prepared two types of discotic cores, PDI and NDI, two types of peripheral units, three-branched G0- and six-branched G1-type dendronized chains, and immiscible chain pairs, alkyl and TEG chains. After recognizing that the combination of PDI and G0


columnar mesophases, we studied $\mathbf{P D I}_{\mathbf{G 1}}$ and $\mathbf{N D I}_{\mathbf{G 0}}$ systems having larger volumes of side chains to the cores. As a result, when the side chain volume becomes much larger, the derivatives having one type of (dodecyl or TEG) peripheral chains adopt micellar cubic, crystalline, or isotropic liquid phases. In sharp contrast, all three compounds having the immiscible side chain pair form rectangular columnar mesophases involving $\pi$-stacked arrays. The dominant reason of the observed preferential formation of columnar phases is the consequence of the exclusion of other phases, where a thermodynamically unfavorable contact between hydrophobic and hydrophilic chains considerably takes place. The molecular design strategy demonstrated here would extend the acceptable range of core/chain volume balance for columnar LC formation and would enable a variety of $\pi$-conjugated motifs to form columnar mesophases by side-chain directed assembly.

\section{Acknowledgements}

This work was supported by a Grant-in-Aid for Young Scientists (B) (26810049) from the Japan Society for the Promotion of Science. We thank Prof. Dr Takuzo Aida and Mr Yoshiki Shibuya in The Univ. of Tokyo for DSC measurements and Dr Akinori Saeki in Osaka Univ. for helpful discussions. The synchrotron radiation experiments were performed at BL44B2 ${ }^{41}$ in SPring-8 with the approval of RIKEN (Proposal No. 20130021).

\section{Notes and references}

1 D. Adam, P. Schuhmacher, J. Simmerer and L. Häussling, Nature, 1994, 371, 141.

2 K. Ohta, K. Hatsusaka, M. Sugibayashi, M. Ariyoshi, K. Ban, F. Maeda, R. Naito and K. Nishizawa, Mol. Cryst. Liq. Cryst., 2003, 397, 325.

3 C. Simpson, J. Wu, M. Watson and K. Mullen, J. Mater. Chem., 2004, 14, 494. 
4 S. Laschat, A. Baro, N. Steinke, F. Giesselmann, C. Haegele, G. Scalia, R. Judele, E. Kapatsina, S. Sauer, A. Schreivogel and M. Tosoni, Angew. Chem., Int. Ed., 2007, 46, 4832.

5 S. Sergeyev, W. Pisula and Y. H. Geerts, Chem. Soc. Rev., 2007, 36, 1902.

6 W. Pisula, M. Zorn, J. Y. Chang, K. Müllen and R. Zentel, Macromol. Rapid Commun., 2009, 30, 1179.

7 T. Kato, T. Yasuda, Y. Kamikawa and M. Yoshio, Chem. Commun., 2009, 729.

8 B. M. Rosen, D. A. Wilson, C. J. Wilson, M. Peterca, B. C. Won, C. Huang, L. R. Lipski, X. Zeng, G. Ungar, P. A. Heiney and V. Percec, J. Am. Chem. Soc., 2009, 131, 17500.

9 P. Sakya, J. M. Seddon, R. H. Templer, R. J. Mirkin and G. J. T. Tiddy, Langmuir, 1997, 13, 3706.

10 K. Borisch, S. Diele, P. Goring, H. Kresse and C. Tschierske, J. Mater. Chem., 1998, 8, 529.

11 T. Yasuda, H. Ooi, J. Morita, Y. Akama, K. Minoura, M. Funahashi, T. Shimomura and T. Kato, Adv. Funct. Mater., 2009, 19, 411.

12 S. N. Chvalun, M. A. Shcherbina, A. N. Yakunin, J. Blackwell and V. Percec, Polym. Sci., Ser. A, 2007, 49, 158.

13 S. Coco, C. Cordovilla, B. Donnio, P. Espinet, M. J. GarciaCasas and D. Guillon, Chem. - Eur. J., 2008, 14, 3544.

14 M. A. Alam, J. Motoyanagi, Y. Yamamoto, T. Fukushima, J. Kim, K. Kato, M. Takata, A. Saeki, S. Seki, S. Tagawa and T. Aida, J. Am. Chem. Soc., 2009, 131, 17722.

15 G. C. Shearman, G. Yahioglu, J. Kirstein, L. R. Milgrom and J. M. Seddon, J. Mater. Chem., 2009, 19, 598.

16 Q. Xiao, T. Sakurai, T. Fukino, K. Akaike, Y. Honsho, A. Saeki, S. Seki, K. Kato, M. Takata and T. Aida, J. Am. Chem. Soc., 2013, 135, 18268.

17 A. Nowak-Kŕol, D. Gryko and D. T. Gryko, Chem. - Asian J., 2010, 5, 904.

18 S. Maruyama, K. Sato and H. Iwahashi, Chem. Lett., 2010, 39, 714.

19 C. Tschierske, J. Mater. Chem., 2001, 11, 2647.

20 M. Lehmann, Chem. - Eur. J., 2009, 15, 3638.

21 X. Feng, V. Marcon, W. Pisula, M. R. Hansen, J. Kirkpatrick, F. Grozema, D. Andrienko, K. Kremer and K. Müllen, Nat. Mater., 2009, 8, 421.

22 T. Sakurai, K. Shi, H. Sato, K. Tashiro, A. Osuka, A. Saeki, S. Seki, S. Tagawa, S. Sasaki, H. Masunaga, K. Osaka, M. Takata and T. Aida, J. Am. Chem. Soc., 2008, 130, 13812.

23 T. Sakurai, K. Tashiro, Y. Honsho, A. Saeki, S. Seki, A. Osuka, A. Muranaka, M. Uchiyama, J. Kim, S. Ha, K. Kato, M. Takata and T. Aida, J. Am. Chem. Soc., 2011, 133, 6537.
24 M.-C. Yeh, Y.-L. Su, M.-C. Tzeng, C. W. Ong, T. Kajitani, H. Enozawa, M. Takata, Y. Koizumi, A. Saeki, S. Seki and T. Fukushima, Angew. Chem., Int. Ed., 2013, 52, 1031.

25 S. Yagai, S. Okamura, Y. Nakano, M. Yamauchi, K. Kishikawa, T. Karatsu, A. Kitamura, A. Ueno, D. Kuzuhara, H. Yamada, T. Seki and H. Ito, Nat. Commun., 2013, 5, 5013.

26 C. Tschierske, Angew. Chem., Int. Ed., 2013, 52, 8828.

27 F. Würthner, C. R. Saha-Möller, B. Fimmel, S. Ogi, P. Leowanawat and D. Schmidt, Chem. Rev., 2015, 115, DOI: 10.1021/acs.chemrev.5b00188.

28 F. Würthner, C. Thalacker, S. Diele and C. Tschierske, Chem. - Eur. J., 2001, 7, 2245.

29 S.-L. Suraru and F. Würthner, Angew. Chem., Int. Ed., 2014, 53, 7428.

30 N. Sakai, J. Mareda, E. Vauthey and S. Matile, Chem. Commun., 2010, 46, 4225.

31 E. Schwartz, V. Palermo, C. E. Finlayson, Y.-S. Huang, M. B. L. Otten, A. Liscio, S. Trapani, I. Gonzalez-Valls, P. Brocorens, J. J. L. M. Cornelissen, K. Peneva, K. Müllen, F. C. Spano, A. Yartsev, S. Westenhoff, R. H. Friend, D. Beljonne, R. J. M. Nolte, P. Samori and A. E. Rowan, Chem. - Eur. J., 2009, 15, 2536.

32 A. Wicklein, A. Lang, M. Muth and M. Thelakkat, J. Am. Chem. Soc., 2009, 131, 14442.

33 J. van Herrikhuyzen, A. Syamakumari, A. P. H. J. Schenning and E. W. Meijer, J. Am. Chem. Soc., 2004, 126, 10021.

34 V. Percec, M. Peterca, T. Tadjiev, X. Zeng, G. Ungar, P. Leowanawat, E. Aqad, M. R. Imam, B. M. Rosen, U. Akbey, R. Graf, S. Sekharan, D. Sebastiani, H. W. Spiess, P. A. Heiney and S. D. Hudson, J. Am. Chem. Soc., 2011, 133, 12197.

35 L.-Y. Chen, T.-H. Ke, C.-C. Wu, T.-C. Chao, K.-T. Wong and C.-C. Chang, Appl. Phys. Lett., 2007, 91, 163509.

36 S. Yagai, T. Seki, T. Karatsu, A. Kitamura and F. Würthner, Angew. Chem., Int. Ed., 2007, 47, 3367.

37 G. J. Clarkson, N. B. McKeown and K. E. Treacher, J. Chem. Soc., Perkin Trans. 1, 1995, 1817.

38 A. A. Levchenko, C. K. Yee, A. N. Parikh and A. Navrotsky, Chem. Mater., 2005, 17, 5428.

39 Y. Tsutsui, T. Sakurai, K. Kato, M. Takata and S. Seki, J. Photopolym. Sci. Technol., 2015, 28, 583.

40 T. Sakurai, Y. Tsutsui, W. Choi and S. Seki, Chem. Lett., 2015, 44, 1401.

41 K. Kato, R. Hirose, M. Takemoto, S. Ha, J. Kim, M. Higuchi, R. Matsuda, S. Kitagawa and M. Takata, AIP Conf. Proc., 2010, 1234, 875 . 